\title{
The influence of frailty syndrome on acceptance of illness in elderly patients with chronic obstructive pulmonary disease
}

This article was published in the following Dove Press journal:

International Journal of COPD

29 September 2016

Number of times this article has been viewed

\author{
Izabella Uchmanowicz' \\ Beata Jankowska-Polanska' \\ Mariusz Chabowski \\ Bartosz Uchmanowicz' \\ Andrzej $\mathrm{M} \mathrm{Fal}^{3}$ \\ 'Department of Clinical Nursing, \\ Faculty of Health Science, Wroclaw \\ Medical University, ${ }^{2}$ Division of \\ Nursing in Surgical Procedures, \\ Department of Clinical Nursing, \\ Faculty of Health Science, Wroclaw \\ Medical University, ${ }^{3}$ Department \\ of Healthcare Organisation and \\ Economics, National Institute of \\ Public Health, National Institute \\ of Hygiene, Warsaw, Poland
}

\begin{abstract}
COPD is one of the most debilitating diseases. Frailty syndrome and advanced age may decrease the acceptance of illness, quality of life, and worsen health conditions in these patients, as well as lead to an increase in health care expenses. The aim of the study was to assess how the level of frailty affects the acceptance of illness in elderly patients with COPD. We also aimed to evaluate the associations between sociodemographic and clinical factors and the level of acceptance of illness, anxiety, and frailty in this group of patients. The study included 102 COPD patients with a mean age of 63.2 (standard deviation $=6.5$ ) years and grades I (3\%), II (37\%), III (52\%), and IV (8\%) by Global Initiative for Chronic Obstructive Lung Disease. The Polish versions of the Acceptance of Illness Scale and Tilburg frailty indicator were used. Frailty syndrome was found in 77 (75.5\%) patients, with an average score of 7.42 (standard deviation $=2.24)$. Coexisting diseases such as hypertension $(46.07 \%)$, coronary artery disease (32.35\%), heart failure (28.43\%), diabetes (18.63\%), and heart arrhythmia $(9.8 \%)$ were found among the subjects. The overall level of acceptance of illness was 20.6 (standard deviation =7.62). A lower level of acceptance of illness was associated with a higher level of frailty, especially in the physical and social domain. Elderly patients with severe COPD are more prone to frailty and decreased acceptance of their disease in comparison to patients with other chronic diseases. Assessment and management of frailty in the care of older COPD patients are likely to improve risk stratification significantly and help personalize management, leading to better patient outcomes.
\end{abstract}

Keywords: frailty syndrome, COPD, acceptance of illness, elderly patients, Tilburg frailty indicator, TFI, Acceptance of Illness Scale, AIS

\section{Introduction}

COPD in one of the most important public health problems and one of the most common chronic diseases. ${ }^{1}$ It is estimated that, in Poland, about 2 million patients suffer from COPD; $80 \%$ of them have either mild or moderate severity airflow limitation. The remaining 20\%, with severe and very severe airflow limitation, require increased use of medical care. ${ }^{2}$ COPD is currently the fourth most common cause of death among adult patients worldwide, but morbidity and mortality are constantly increasing. ${ }^{3}$ It has been projected that, by 2020, COPD will be the third most common cause of diseaserelated deaths. ${ }^{4,5}$ In the population of $>60$ years of age, COPD is a serious problem because diagnosis is often delayed by nonspecific symptoms. In elderly people with advanced COPD, exacerbations occur more frequently than in younger populations and are associated with an increased risk of acute respiratory failure. Polypharmacy, which is common in elderly patients, may additionally increase the risk of side effects
Correspondence: Mariusz Chabowski Department of Surgery, 4th Military Teaching Hospital, 5 Weigla Street, 50-98I Wroclaw, Poland

Tel +4826I 660247

Fax $+4826 I 660245$

Email mariusz.chabowski@gmail.com (c)
hereby accept the Terms. Non-commercial uses of the work are permitted without any further permission from Dove Medical Press Limited, provided the work is properly attributed. For permission hereby accept the Terms. Non-commercial uses of the work are permitted without any further permission from Dove Medie
for commercial use of this work, please see paragraphs 4.2 and 5 of our Terms (https://www.dovepress.com/terms.php). 
as these patients take many drugs for numerous diseases. Polypharmacy and possible drug interactions may hamper disease management. Elderly patients with COPD are also at an increased risk of developing frailty syndrome (FS) and problems with disease acceptance. ${ }^{6,7}$

FS often coexists with chronic diseases. It increases the risk of adverse health events and is strongly associated with a decrease in mobility, an increased risk of falls, polypharmacy, comorbidities, a decrease in cognitive function, and malnutrition. ${ }^{8}$ On the one hand, FS can be regarded as a consequence of aging, but on the other, it is associated with many chronic diseases that increase patient disability, hospitalization rates, costs of health care, and mortality. To date, frailty has been assessed in patients with many chronic diseases, such as cardiovascular diseases, obesity, renal insufficiency, but little is known about the coexistence of frailty with COPD in elderly patients. ${ }^{8-11}$ Moreover, the impact of FS on the acceptance of illness in elderly COPD patients remains unclear.

The aim of the study was to assess how the level of frailty affects the acceptance of illness in elderly patients with COPD. We also aimed to evaluate the associations between sociodemographic and clinical factors and the level of acceptance of illness, anxiety, and frailty in this group of patients.

\section{Methods}

The study was conducted among 102 patients with COPD hospitalized due to exacerbation of their condition in the Department of Internal Medicine of Lower Silesian Centre for Pulmonary Diseases in Wroclaw between March 2014 and June 2015. Participation in the study was both voluntary and confidential. All the patients were informed about the aims of the study and the right to withdraw from the research at any time. The study was approved by the Commission of Bioethics at Wroclaw Medical University (consent no KB-683/2014).

Inclusion criteria were as follows:

1. Diagnosis of COPD according to the American Thoracic Society/European Respiratory Society in the history at least 1 year before entering the study. ${ }^{12}$

2. Written informed consent for participation in the study. Exclusion criteria were as follows:

1. Coexistence of other chronic pulmonary disease such as asthma, active tuberculosis, lung cancer, bronchiectasis, sarcoidosis, pulmonary fibrosis, primary pulmonary hypertension, interstitial lung disease, or other active lung disease.
2. Hemodynamic instability and severe exacerbation of any concomitant chronic disease.

3. The diagnosis of severe mental disorders requiring psychiatric treatment.

4. Lack of consent for participation in the study.

In this study, an integral model of frailty developed by Gobbens was used as a conceptual basis. This model was chosen because it incorporates a more holistic approach to frailty going beyond the physical approach, which is the basis for most models of frailty. The conceptual model defines frailty using indicators from three domains: physical, psychological, and social. ${ }^{13}$

In the study, standardized questionnaires were used and an analysis of medical records was done in order to collect information about diagnosis, severity of the disease, spirometry results, and treatment administered.

1. The survey produced by the authors included 18 questions related to sociodemographic and clinical data (sex, age, education, number of cigarettes smoked, frequency of hospitalizations, knowledge about the disease, and drugs administered by inhalation).

2. The Acceptance of Illness Scale (AIS) developed by Felton et al and adapted to Polish conditions by Jurczyński included eight statements and allowed assessment of the degree of illness acceptance by the patient. ${ }^{14,15}$ The greater the acceptance of the disease, the less severe the negative reactions and emotions associated with the disease. Each of the statements included a 5-score scale. The patients described their current well-being by indicating the corresponding number: 1 -strongly agree; 2 - agree; 3 - undecided; 4 - disagree; 5 - strongly disagree. Wherein, 1 means a bad adaptation to disease and 5 the highest acceptance of the given condition. The adaptation to the disease is the sum of all the points and is between 8 and 40 points. The authors believe it can be applied to assess any type of disease. ${ }^{14}$

3. The Tilburg frailty indicator (TFI) consists of two different parts. One addresses potential determinants of frailty: the participant's sociodemographic characteristics (sex, age, marital status, country of origin, educational level, and monthly income), lifestyle, multimorbidity, life events, and living environment. The second part addresses the components of frailty. Part two of the TFI comprises 15 selfreported questions, divided into three domains. The physical domain ( $0-8$ points) consists of eight questions related to physical health, unexplained weight loss, difficulty in walking, balance, hearing problems, vision problems, strength in hands, and physical tiredness. The psychological domain 
(0-4 points) comprises four items related to cognition, depressive symptoms, anxiety, and coping. The social domain (0-3 points) comprises three questions related to living alone, social relations, and social support. Eleven items in part two of the TFI have two response categories ("yes" and "no"), while the other items have three ("yes", "no", and "sometimes"). "Yes" or "sometimes" responses are scored 1 point each, while "no" responses are scored 0 . The instrument's total score may range from 0 to 15 : the higher the score, the higher one's frailty. Frailty is diagnosed when the total TFI score is $\geq 5 .{ }^{16}$ In the present study, the Polish version of the TFI questionnaire was used. ${ }^{17}$

\section{Statistical analysis}

The results were analyzed with Statistica software version 6 (StatSoft, Tulsa, OK, USA). Means, medians, and standard deviations (SDs) were calculated for the variables examined. To assess the differences, Student's $t$-test was applied. Two-way analysis of variance allowed the impact of frailty on acceptance of the disease to be estimated. Pearson's correlation was used to measure the correlation between sociodemographic and clinical variables and the levels of illness acceptance (AIS), anxiety, and frailty (TFI).

\section{Results}

The study was conducted in 102 patients with COPD, of whom $37.25 \%$ were women. The average age of those surveyed was 63.2 years $(\mathrm{SD}=6.5$ ). More than one-half of the respondents were married or lived in partnerships (57.8\%). The majority lived in cities $(60.8 \%)$ and had secondary $(55.6 \%)$ or vocational $(26.5 \%)$ education. They received knowledge about the disease from medical personnel (39.2\% from nurses and $37.3 \%$ from doctors). More than one-half of the respondents $(58.8 \%)$ claimed that the level of their knowledge was insufficient (Table 1).

The majority of the patients had suffered from COPD for $10-15$ years (33.3\%). Subsequently, there were people with a 5 - to 10 -year disease history $(27.5 \%)$ and those who had been ill for more than 15 years $(22.6 \%)$. Most patients were at the III (severe) (52\%) and II (moderate) (37\%) stage of disease by Global Initiative for Chronic Obstructive Lung Disease. Spirometric classification for the group was: forced expiratory volume in 1 second 1.36 , forced vital capacity $49 \% \mathrm{~N}$, and fixed ratio (forced expiratory volume in $1 \mathrm{~second} /$ forced vital capacity) 0.61 . All the patients were exposed to the main risk factor of COPD and $50 \%$ of respondents had smoked for longer than 15 years. Fewer than $30 \%$ of respondents smoked up to ten cigarettes per day, the
Table I Sociodemographic characteristics of the studied patients

\begin{tabular}{|c|c|c|}
\hline Characteristics & $\mathbf{N}$ & $\%$ \\
\hline \multicolumn{3}{|l|}{ Sex } \\
\hline Men & 64 & 62.75 \\
\hline Women & 38 & 37.25 \\
\hline \multicolumn{3}{|l|}{ Marital status } \\
\hline Married/in a relationship & 59 & 57.84 \\
\hline Separated/divorced & 22 & 22.57 \\
\hline Widow/widower & 21 & 20.59 \\
\hline \multicolumn{3}{|l|}{ Education } \\
\hline Vocational/primary & 27 & 26.47 \\
\hline Preuniversity & 57 & 55.88 \\
\hline Higher vocational/university & 14 & 13.73 \\
\hline Data not available & 4 & 3.92 \\
\hline \multicolumn{3}{|l|}{ Place of residence } \\
\hline Rural area & 40 & 39.22 \\
\hline Urban area & 62 & 60.78 \\
\hline \multicolumn{3}{|l|}{ Knowledge about COPD } \\
\hline I believe I know everything on this topic & 7 & 6.86 \\
\hline I know as much as I need to know & 33 & 32.35 \\
\hline I know too little & 60 & 58.82 \\
\hline I do not know and I do not want to know & 2 & 1.96 \\
\hline \multicolumn{3}{|c|}{$\begin{array}{l}\text { The most useful sources of information helpful in coping } \\
\text { with the disease }\end{array}$} \\
\hline Conversation with a doctor & 38 & 37.25 \\
\hline Conversation with a nurse & 40 & 39.21 \\
\hline Books, leaflets & 19 & 18.63 \\
\hline Television & 5 & 4.9 \\
\hline
\end{tabular}

Abbreviation: $\mathrm{N}$, number of patients.

others smoked 10-20 (39.2\%) or even more than 20 (31.4\%); $40.2 \%$ of patients reported aggravation of symptoms more than twice a day, $16.7 \%$ every day, and $24.5 \%$ several times a week. More than one-half of the respondents (55.9\%) complained of waking up from sleep due to being short of breath three nights or more a week. Only $16.7 \%$ of respondents reported no symptoms during the night. Among the subjects, $64.7 \%$ believed that they take inhaled medications skillfully, $10.8 \%$ of them were given oxygen therapy at home, and over $60 \%$ had been hospitalized during the past 12 months due to exacerbations. In addition, the respondents' diagnosed comorbidities included hypertension $(46.07 \%)$, coronary artery disease $(32.35 \%)$, heart failure $(28.43 \%)$, diabetes (18.63\%), and heart arrhythmia (9.8\%) (Table 2).

The assessment of illness acceptance with the use of AIS questionnaire revealed that respondents are mostly characterized by a moderate acceptance level with a tendency to a lack of acceptance of their disease (mean 20.6; SD =7.62). Patients worried most about the limitation of their self-sufficiency (mean 2.2; $\mathrm{SD}=1.20$ ), but least about being a burden on their family and friends (mean 3.1; SD =1.10) (Table 3).

FS was found in 77 patients. The minimal TFI score was 3 , maximum 12, and average $7.42(\mathrm{SD}=2.24)$ (Table 4). 
Table 2 Clinical characteristics of the studied patients

\begin{tabular}{|c|c|c|}
\hline \multicolumn{3}{|l|}{ Clinical characteristics } \\
\hline Spirometry & Mean (SD) & Range \\
\hline $\mathrm{FEV}_{1}(\mathrm{~L})$ & $\mathrm{I} .36(0.7)$ & $0.5 I-3.50$ \\
\hline $\mathrm{FEV}_{1} \% \mathrm{~N}$ & $49(16.3)$ & $15-87$ \\
\hline Ratio of FEV, to FVC (Tiffeneau index) & $0.61(0.17)$ & $0.4 I-0.7$ \\
\hline Characteristics & $\mathbf{N}$ & $\%$ \\
\hline \multicolumn{3}{|l|}{ Duration of the disease } \\
\hline $0-5$ years & 17 & 16.67 \\
\hline $5-10$ years & 28 & 27.45 \\
\hline $10-15$ years & 34 & 33.33 \\
\hline Longer than 15 years & 23 & 22.55 \\
\hline \multicolumn{3}{|l|}{ Disease severity by GOLD } \\
\hline 1 & 3 & 3 \\
\hline II & 38 & 37 \\
\hline III & 53 & 52 \\
\hline IV & 8 & 8 \\
\hline \multicolumn{3}{|l|}{ Comorbidities } \\
\hline Hypertension & 47 & 46.07 \\
\hline Coronary artery disease & 33 & 32.35 \\
\hline Heart failure & 29 & 28.43 \\
\hline Diabetes & 19 & 18.63 \\
\hline Heart arrhythmia & 10 & 9.80 \\
\hline \multicolumn{3}{|l|}{ Duration of smoking } \\
\hline $0-5$ years & 22 & 21.57 \\
\hline $5-10$ years & 9 & 8.82 \\
\hline $10-15$ years & 20 & 19.61 \\
\hline Longer than 15 years & 51 & 50.00 \\
\hline \multicolumn{3}{|l|}{ The number of cigarettes smoked per day } \\
\hline $0-10$ & 30 & 29.41 \\
\hline $10-20$ & 40 & 39.22 \\
\hline More than 20 & 33 & 31.37 \\
\hline \multicolumn{3}{|c|}{ Frequency of dyspnea exacerbations during last month } \\
\hline Once a day & 17 & 16.67 \\
\hline More often than twice a day & 41 & 40.20 \\
\hline Several times a week & 25 & 24.51 \\
\hline Only after physical effort & 19 & 18.63 \\
\hline \multicolumn{3}{|c|}{ Frequency of awakening due to COPD symptoms during the last month } \\
\hline Once a week & 28 & 27.45 \\
\hline Three nights a week or more often & 57 & 55.88 \\
\hline None & 17 & 16.67 \\
\hline \multicolumn{3}{|c|}{ Hospitalization due to exacerbation of COPD during the last 12 months } \\
\hline Yes & 62 & 60.78 \\
\hline No & 40 & 39.22 \\
\hline \multicolumn{3}{|l|}{ Ability of taking inhaled medications } \\
\hline Yes & 66 & 64.71 \\
\hline No & 36 & 35.29 \\
\hline \multicolumn{3}{|l|}{ The use of oxygen at home } \\
\hline Yes & 11 & 10.78 \\
\hline No & 91 & 89.22 \\
\hline
\end{tabular}

Abbreviations: $\mathrm{FEV}_{1}$, forced expiratory volume in I second; $\mathrm{FEV}_{1} \% \mathrm{~N}$, forced expiratory volume in I second \% of output value; FVC, forced vital capacity; GOLD, Global Initiative for Chronic Obstructive Lung Disease; N, number of patients; SD, standard deviation.

Pearson's correlation was used to evaluate associations between illness acceptance and the results of the TFI scale. This showed that a higher level of the physical and social domain of TFI correlated with a lower level of illness acceptance (Table 5).

\section{Discussion}

In our study, FS was found in $75.5 \%$ of elderly COPD patients. Acceptance of illness was moderate with a tendency to a lack of acceptance of the disease. A lower level of acceptance of illness was associated with a higher level of the physical and social domain of the TFI score. To the best of our knowledge, this is the first study that addresses frailty and its effect on illness acceptance in elderly patients with COPD; therefore, identification of the specific indicators that lead to the development of frailty in these patients may help to improve their quality of life and health care utilization, as well as reduce mortality and morbidity.

Earlier definitions of FS were based on the frailty model developed at the turn of the 1980s and 1990s. According to this model, the main symptoms of frailty included body weight loss, fatigue, slowing, weakness, and reduced physical activity. ${ }^{18,19}$ In 2013, a group of six international associations dealing with frailty issues defined FS as:

A medical syndrome with multiple causes and contributors that is characterized by diminished strength, endurance, and reduced physiologic function that increases an individual's vulnerability for developing increased dependency and/or death. ${ }^{20}$

At present, frailty becomes more and more important due to increasing life expectancy. Additionally, it is related to the increased risk of unfavorable health events, which are strongly associated with reduced physical fitness, an increased risk of falls, polypharmacy, comorbidities, decrease in cognitive function, and malnutrition. ${ }^{18}$ Possible pathophysiological causes of frailty include the predominance of catabolic processes, ongoing chronic inflammatory processes, immune system dysfunction, impaired neuroendocrine regulation, and metabolic disorders. ${ }^{8}$ On the one hand, frailty is a consequence of advanced age, but on the other, it is associated with multiple chronic diseases and as such, it increases disability, hospitalization rates, the cost of health care, and mortality. Only systematic assessment of FS enables risk stratification and the introduction of proper therapeutic strategies focused on the needs of elderly patients and their quality of life along with the effective use of health care resources.

Frailty impairs biopsychosocial functioning, which can affect the acceptance of illness among COPD patients. COPD is an irreversible and progressive disease. Patients with COPD experience intermittent exacerbations, characterized by acute deterioration in chronic dyspnea and functional limitation. They are more likely to be frail, as it is with people who 
Table 3 Descriptive statistics for the questions of AIS

\begin{tabular}{lll}
\hline Questions from AIS questionnaire & Mean (SD) & Median (quartile I-III) \\
\hline I have problems with adjusting to the limitations imposed by the disease & $2.4(0.97)$ & $2(2-3)$ \\
Due to my health condition, I am not able to do what I like the most & $2.2(0.95)$ & $2(2-3)$ \\
The disease makes me feel unwanted & $3(3.29)$ & $3(2-3)$ \\
Health problems make me more dependent on others than I would like to be & $2.4(I . I I)$ & $2(2-3)$ \\
The disease makes me a burden for my family and friends & $3.1(I . I 0)$ & $3(2-4)$ \\
Due to my health condition I do not feel to be a really valuable man & $2.4(I .19)$ & $2(2-3)$ \\
I will never be as self-sufficient to the extent to which I would like to be & $2.2(1.20)$ & $2(1-3)$ \\
I believe people that stay with me are often embarrassed because of my disease & $20.6(7.62)$ & $3(2-3)$ \\
Overall level of acceptance of illness & & $19(16-24)$
\end{tabular}

Abbreviations: AIS, Acceptance of Illness Scale; SD, standard deviation.

have other advanced chronic diseases. ${ }^{9,10,21}$ Chronic disease requires the patient to adapt to a number of limitations and participate in the treatment process. Diagnosis of chronic disease and loss of health demand from a patient that they implement multidimensional and continuous changes introduced in the scope of physical, mental, and social functioning. This process, similar to that in cancer diseases, is the way to acceptance not only associated with death, but of the need to adapt to the limitations imposed by chronic illness.

The degree of illness acceptance has been evaluated in many chronic diseases such as diabetes, arterial hypertension, renal failure, respiratory diseases, and diseases of the nervous system. The results of these studies indicate medium adaptation and acceptance of illness across many various chronic entities. Researchers claim that the fact of being chronically ill has an impact on the level of acceptance of illness and quality of life independent of diagnosis. ${ }^{15,22}$ Adaptation to illness plays an important role in chronic diseases, which requires a different approach, including taking into account aspects such as patients' acceptance of illness. ${ }^{23}$ Acceptance of illness is one of the most important stages in a patient's adaptation to his or her disease. It facilitates the adaptation process during which a patient adjusts to the new conditions of living with a disease.

In the present study, the mean level of acceptance of illness was 20.6 (on a range from 8 to 40 ). The results are

Table 4 Descriptive statistics for Tilburg frailty indicator

\begin{tabular}{|c|c|c|c|}
\hline Part B components of frailty & Yes & Sometimes & No \\
\hline \multicolumn{4}{|l|}{ BI physical components } \\
\hline II. Do you feel physically healthy? & 19 & & 83 \\
\hline 12. Have you lost a lot of weight recently without wishing to do so? & 32 & & 69 \\
\hline \multicolumn{4}{|l|}{ Do you experience problems in your daily life due to } \\
\hline 13. difficulty in walking? & 41 & & 56 \\
\hline I4. difficulty maintaining your balance? & 30 & & 64 \\
\hline I5. poor hearing? & 24 & & 68 \\
\hline 16. poor vision? & 53 & & 40 \\
\hline I7. lack of strength in your hands? & 77 & & 18 \\
\hline 18. physical tiredness? & 98 & & 3 \\
\hline \multicolumn{4}{|l|}{ B2 psychological components } \\
\hline 19. Do you have problems with your memory? & 21 & 0 & 80 \\
\hline 20. Have you felt down during the last month? & 5 & 87 & 6 \\
\hline 21. Have you felt nervous or anxious during the last month? & 34 & 4 & 62 \\
\hline 22. Are you able to cope with problems well? & 47 & & 52 \\
\hline \multicolumn{4}{|l|}{ B3 social components } \\
\hline 23. Do you live alone? & 31 & & 69 \\
\hline 24. Do you sometimes miss having people around you? & 40 & 14 & 48 \\
\hline 25. Do you receive enough support from other people? & 71 & & 31 \\
\hline Frailty in the studied group $M(S D)$; min-max & $7.42(2.24)$ & $3-12$ & \\
\hline Frailty syndrome & 77 & & 25 \\
\hline Physical domain M (SD); min-max & $4.15(1.95)$ & $0-8$ & \\
\hline Psychological domain M (SD); min-max & $2.13(1.07)$ & $0-4$ & \\
\hline Social domain M (SD); min-max & I.18 (0.89) & $0-3$ & \\
\hline
\end{tabular}

Abbreviations: max, maximum; M, mean; min, minimum; SD, standard deviation. 
Table 5 Correlation coefficients between the level of illness acceptance and results of TFI scale in the study group

\begin{tabular}{ll}
\hline Variables of TFI scale & Acceptance of illness scale \\
\hline Physical domain of TFI & $-0.36^{*}$ \\
Psychological domain of TFI & 0.06 \\
Social domain of TFI & $-0.24^{*}$ \\
The level of frailty & -0.35
\end{tabular}

Note: *Statistical significance at a level of $P<0.05$.

Abbreviation: TFI, Tilburg frailty indicator.

lower than those obtained by Niedzielski et al. In their study, the average level of acceptance of illness was 25 points, but was insignificantly lower in older patients and in those with earlier onset. ${ }^{24}$ The worse acceptance of illness obtained in our study is due to the characteristics of the experimental group, which included elderly patients (mean age 63.2 years) with a long history of COPD ( $56 \%$ had been ill for 10 years and longer) and exacerbations.

FS was diagnosed in over $75 \%$ of our COPD patient group. Newman et al reported a $51 \%$ prevalence of frailty among patients with subclinical cardiovascular disease, but many of those patients were younger with less advanced disease. ${ }^{11}$ Park et al reported $57.8 \%$ of frailty among COPD patients; however, their study sample was not homogeneous and also included patients with chronic bronchitis. ${ }^{25}$ The frailty index in the present study accounted for a score of 7.42 ( $\mathrm{SD}=2.24$ ) scores, which indicates a high degree of frailty in COPD patients. The highest TFI score was reported in the physical domain - 4.15 $(\mathrm{SD}=1.19)$.

The present study shows that coexistence of FS negatively affects the level of acceptance of illness, especially in the social domain. Lack of support hampers adaptation to a disease. Additionally, deterioration of possibilities in terms of physical activity as measured by the TFI scale was a determinant of the decreased level of illness acceptance. Other researchers report similar observations. The association between acceptance of illness and patients' age, self-reliance in difficult situations and a sense of their own disease in patients with leukemia, ${ }^{26}$ as well as the living environment in elderly people ${ }^{27}$ was revealed by other researchers. In a study by Jankowska-Polanska et al, the acceptance of a disease significantly impacts on the perception of quality of life in patients with COPD - the greater the acceptance, the higher the quality of life rating. ${ }^{28}$

\section{Conclusion}

Elderly patients with severe COPD may be more prone to frailty and decreased acceptance of their disease in comparison to patients suffering from other chronic diseases.
The level of frailty, especially in the physical and social domain, translates into lower acceptance of illness in this group of patients. Assessment and management of frailty in the care of older COPD patients are likely to significantly improve risk stratification and help personalize management, leading to better patient outcomes.

\section{Disclosure}

The authors report no conflicts of interest in this work.

\section{References}

1. Mannino DM. Chronic obstructive pulmonary disease: definition and epidemiology. Respir Care. 2003;48(12):1185-1191.

2. Zieliński J. [Chronic Obstructive Pulmonary Disease]. 4th ed. Wrocław: Górnicki Wydawnictwo Medyczne; 2007. Polish.

3. Vestbo J, Hurd SS, Agusti AG, et al. Global strategy for the diagnosis, management, and prevention of chronic obstructive pulmonary disease: GOLD executive summary. Am J Respir Crit Care Med. 2013; 187(4):347-365.

4. Petty TL. Definition, epidemiology, course, and prognosis of COPD. Clin Cornerstone. 2003;5(1):1-10.

5. Jemal A, Ward E, Hao Y, Thun M. Trends in the leading causes of death in the United States, 1970-2002. JAMA. 2005;294(10):1255-1259.

6. Hanania NA, Sharma G, Sharafkhaneh A. COPD in the elderly patient. Semin Respir Crit Care Med. 2010;31(5):596-606.

7. Panaszek B. [Bronchial Asthma and COPD - Separate Approach to Diagnosis and Treatment in Elderly]. 1st ed. 2010:41-45. Polish.

8. Uchmanowicz I, Lisiak M, Wontor R, et al. Frailty syndrome in cardiovascular disease: clinical significance and research tools. Eur $J$ Cardiovasc Nurs. 2015;14(4):303-309.

9. Blaum CS, Xue QL, Michelon E, Sembra RD, Fried LP. The association between obesity and the frailty syndrome in older women: the Women's Health and Aging Studies. J Am Geriatr Soc. 2005;53(6): 927-934.

10. Cigolle CT, Ofstedal MB, Tian Z, Blaum CS. Comparing models of frailty: the Health and Retirement Study. J Am Geriatr Soc. 2009;57(5): 830-839.

11. Newman AB, Gottdiener JS, McBurnie MA, Hirsch CH, Kop WJ, Tracy R. Associations of subclinical cardiovascular disease with frailty. J Gerontol A Biol Sci Med Sci. 2001;56(3):M158-M166.

12. American Thoracic Society/European Respiratory Society Task Force. Standards for the Diagnosis and Management of Patients with COPD. New York: American Thoracic Society. [updated September 8, 2005]. Available from: http://www.thoracic.org/go/copd. Accessed March 21, 2016.

13. Gobbens RJ, van Assen MA. Frailty and its prediction of disability and health care utilization: the added value of interviews and physical measures following a self-report questionnaire. Arch Gerontol Geriatr. 2012;55(2):369-379.

14. Jurczyński Z. [Measurement Tools in the Promotion of Health and Psychooncology]. Warszawa: Pracownia Testów Psychologicznych; 2009:162-166. Polish.

15. Felton BJ, Revenson TA, Hinrichsen GA. Stress and coping in the explanation of psychological adjustment among chronically ill adults. Soc Sci Med. 1984;18(10):889-898.

16. Uchmanowicz I, Jankowska-Polanska B, Uchmanowicz B, Manulik S, Loboz-Grudzien K, Gobbens RJ. Validity and reliability of the Polish version of the Tilburg Frailty Indicator (TFI). J Frailty Aging. 2016; $5(1): 27-32$.

17. Uchmanowicz I. [The influence of frailty syndrome on the assessment of illness acceptance in elderly patients with chronic heart failure]. J PsycholPharmacol. 2007;58(Suppl 5):647-655. Polish. 
18. Uchmanowicz I, Lisiak M, Jankowska-Polańska B. [Research instruments used in the assessment of the frailty syndrome]. Gerontologia Polska. 2014;22:1-8. Polish.

19. Uchmanowicz I, Loboz-Rudnicka M, Szelag P, Jankowska-Polanska B, Loboz-Grudzień K. Frailty in heart failure. Curr Heart Fail Rep. 2014; 11(3):266-273.

20. Morley JE, Vellas B, van Kan GA, et al. Frailty consensus: a call to action. J Am Med Dir Assoc. 2013;14(6):392-397.

21. Kurpas D, Mroczek B, Knap-Czechowska H, et al. Quality of life and acceptance of illness among patients with chronic respiratory diseases. Respir Physiol Neurobiol. 2013;187(1):114-117.

22. Jankowska-Polanska B, Ilko A, Wleklik M. [Influence the acceptance of the disease on quality of life of patients with hypertension]. Arterial Hypertension. 2014;18:1-8. Polish.

23. Skrzypulec V, Drosdzol A, Nowosielski K. The influence of bronchial asthma on the quality of life and sexual functioning of women. JPhysiol Pharmacol. 2007;58 Suppl 5:647-655.
24. Niedzielski A, Humeniuk E, Tarkowski Z. [Level of disease acceptance in selected diseases]. Fam Med Prim Care Rev. 2005;7:823. Polish.

25. Park SK, Richardson CR, Holleman RG, Larson JL. Frailty in people with COPD, using the National Health and Nutrition Evaluation Survey dataset (2003-2006). Heart Lung. 2013;42(3):163-170.

26. Wiraszka G, Lelonek B. [The functioning of a patient with leukemia and acceptance of oncology disease]. Studia Med. 2008;10:21-26. Polish.

27. Kaczmarczyk M. [The acceptance of the disease in older people living in different environments]. Stud Med. 2008;12:29-33. Polish.

28. Jankowska-Polanska B, Kasprzyk M, Chudiak A. Relation between illness acceptance and quality of life in patients with chronic obstructive pulmonary disease (COPD). Pneumonol Alergol Pol. 2016;84(1): 3-10.

\section{Publish your work in this journal}

The International Journal of COPD is an international, peer-reviewed journal of therapeutics and pharmacology focusing on concise rapid reporting of clinical studies and reviews in COPD. Special focus is given to the pathophysiological processes underlying the disease, intervention programs, patient focused education, and self management protocols.

\section{Dovepress}

This journal is indexed on PubMed Central, MedLine and CAS. The manuscript management system is completely online and includes a very quick and fair peer-review system, which is all easy to use. Visit http://www.dovepress.com/testimonials.php to read real quotes from published authors.

Submit your manuscript here: http://www.dovepress.com/international-journal-of-chronic-obstructive-pulmonary-disease-journal 